\title{
Recurrence of dental trauma and management of pulp revascularized tooth: a case report
}

\begin{abstract}
Pulp revascularization treatment has the potential benefit to increase thickness of root walls and root length of immature necrotic teeth. Dental trauma is the most frequent etiology of pulp necrosis in immature teeth, and its recurrence is frequent in children. To date, no study presented a case report of recurrence of dental trauma in a pulp revascularized tooth. Therefore, the objective of this case report is to describe a clinical management of a traumatized immature necrotic tooth that was first treated with pulp revascularization and suffered a second dental trauma, being then treated with a an alternative filling therapy. A 9-year-old girl suffered fall from a chair one year previously. Considering the late occurrence of the trauma, diagnosis of pulp necrosis and the presence of open apex, the treatment of choice to the right maxillary central incisor was pulp revascularization using the combination of calcium hydroxide and $2 \%$ chlorhexidine gel as intra canal medication. Patient returned after 1 year of pulp revascularization, due to the recurrence of dental trauma 1 month previously. A second endodontic intervention of the right maxillary central incisor was accomplished with an alternative filling therapy (filling paste composed by calcium hydroxide, $2 \%$ chlorhexidine gel and zinc oxide). In conclusion, pulp revascularization is an effective therapy for permanent immature necrotic teeth that suffered dental trauma. However, there is a high risk of recurrence of dental trauma, which may interfere in the treatment success. Therefore, professionals should be prepared for the necessity of alternative measures and techniques according to the evolution of each case.
\end{abstract}

Keywords: dental trauma, immature necrotic teeth, regenerative endodontic procedures, treatment outcomes
Volume 9 Issue 4 - 2018

\author{
Marina Carvalho Prado, Ana Carolina \\ Correia Laurindo de Cerqueira Neto, Pabla \\ Secchi, Andrea Cardoso Pereira, Brenda \\ Paula Figueiredo de Almeida Gomes, Adriana \\ de Jesus Soares
}

Department of Restorative Dentistry, Endodontics Division, State University of Campinas (FOP-UNICAMP), Brazil

Correspondence: Marina Carvalho Prado, Department of Restorative Dentistry, Area of Endodontics, Piracicaba Dental School, State University of Campinas (FOP-UNICAMP), Piracicaba, SP, Brazil, Email marinaprado@dentistas.com.br

Received: July 25, 2018 | Published: August 02, 2018

\section{Introduction}

Dental trauma is classified among the most serious oral conditions, representing a psychological, social and therapeutic problem. The high frequency found in dental trauma is mainly due to increase in violence rates and the large participation of children in sports activities. ${ }^{1-3}$ Moreover, recurrence in dental trauma are frequent in children, occurring from $19.4 \%-49 \%$ of patients. ${ }^{4-6}$ It should be taken into consideration that trauma recurrence in the same tooth affects the success of endodontic treatment and shorten its longterm prognosis. ${ }^{4,7}$ The therapeutic measures regarding dental trauma depends on the type of trauma, pulp and periapical conditions and stage of root development. ${ }^{8}$ In cases of permanent immature necrotic teeth, pulp revascularization is currently considered the first treatment option..$^{9}$ Ideally, this procedure allows not only the resolution of signs and symptoms, but also for the formation of a biological tissue into the intraradicular space while maintaining nociception; leading to an increase in root thickness and root length of previously thin, fractureprone dentinal walls. ${ }^{10-13}$ To the best of the authors knowledge, this is the first study to present a case report of recurrence of dental trauma in a pulp revascularized tooth. Therefore, the objective of this case report is to describe the clinical management of a traumatized immature necrotic tooth that was first treated with pulp revascularization and suffered a second dental trauma, being then treated with a an alternative filling therapy.

\section{Case presentation}

This study was approved by the ethics research committee of Piracicaba Dental School, State University of Campinas (46653015.0.0000.5418) and followed "CARE Checklist" (http:// www.care-statement.org/resources/checklist). A 9-year-old girl was referred to the Dental Trauma Service of Piracicaba Dental School - State University of Campinas (FOP-UNICAMP), Brazil, having fallen from a chair at home one year previously. No emergency treatment was carried out following trauma. Patient's main complaints were suppuration and aesthetic conditions related to dental trauma. Anamnesis demonstrated absence of systemic conditions. In extra oral examination, it was observed that the patient presented inadequate lip closure. Intraoral examination revealed that maxillary right central incisor had enamel dentine fracture without involvement of the pulp, associated with sinus tract. Clinical and radiographic exams were performed (Table 1), demonstrating pulp necrosis and incomplete root formation of this tooth. Considering the late occurrence of the trauma (one year earlier), the unquestionable diagnosis of pulp necrosis and the presence of open apex, the treatment of choice was pulp revascularization using the combination of calcium hydroxide and $2 \%$ chlorhexidine gel as intracanal medication. A complete explanation of the treatment procedures, risks and benefits was accomplished and an informed consent was obtained from the patient's legal guardian.

\section{Therapeutic intervention}

An experienced endodontic specialist performed pulp revascularization according to Nagata et al., ${ }^{14}$ with modifications. Infiltrative anesthesia with $2 \%$ lidocaine and 1:100.000 epinephrines (Alphacaine; DFL, Rio de Janeiro, RJ, Brazil) was applied, and distance field isolation of the tooth was obtain with a rubber dam. Operative field was disinfected with $2 \%$ chlorhexidine gel on a cotton swab. Then, access cavity was prepared using a diamond bur (KG Sorensen ${ }^{\mathrm{TM}}$, Barueri, Brazil) with copious irrigation. Teeth full length was initially determined with Apixia digital imaging software (Apixia, 
Industry, CA, USA), followed by the use of an electronic apex locator (Root ZX Mini; J. Morita Brazil, São Paulo, SP, Brazil). Working length was established $4 \mathrm{~mm}$ short of the total root length, due to the injection of chemical solution. Root disinfection was obtained with no mechanical preparation. Passive decontamination protocol included slow and careful irrigation with $10 \mathrm{~mL}$ of each solution in the following sequence: $6 \%$ sodium hypochlorite (Drogal, Piracicaba, SP, Brazil), saline solution for neutralization, $2 \%$ chlorhexidine (Drogal) and saline solution as the final irrigation. The root canal was dried with the aid of capillary tip (Ultradent products, South Jordan, UT, USA) $3 \mathrm{~mm}$ short of the total root length. After that, root canal was filled with an intracanal medication paste composed by calcium hydroxide (Biodinâmica, Ibiporã, PR, Brazil) and $2 \%$ chlorhexidine gel (Endogel, Itapetininga, SP, Brazil) as the vehicle, in the proportion of 1:1. This intracanal medication was inserted with a lentulo spiral (Dentsply Maillefer ${ }^{\mathrm{TM}}$, Tulsa, OK, USA). Following this, the tooth was sealed with Coltosol (Coltène/WhaledentTM, Mahwah, NJ, USA) and composite resin (Filtek 3M ESPE ${ }^{\mathrm{TM}}$, Sumaré, Brazil) (Figure 1). Second appointment was rescheduled in 3 weeks and remission of clinical signs and symptoms was observed. Tooth was prepared as previously described. Intra canal medication was removed with $10 \mathrm{~mL}$ of saline solution. A final irrigation with $3 \mathrm{~mL}$ of $17 \%$ EDTA (Fórmula e Ação ${ }^{\mathrm{TM}}$, São Paulo, Brazil) was accomplished during 3 minutes, followed by irrigation with saline solution. The root canal space was then dried as previously described. In order to induce bleeding into the root canal, a \#35 manual k-file (Dentsply Maillefer, Ballaigues, Switzerland) was placed at 3-4 $\mathrm{mm}$ beyond the apical foramen. A collagen matrix (CollaCote; Zimmer Dental, Carlsbad, CA, USA) was inserted above the blood clot and then a 3-mm cervical sealing was applied. Despite being the most used material for cervical sealing in pulp revascularization, mineral trioxide aggregate is associated with significant crown discoloration. ${ }^{15,16}$ For this reason, in the present study, cervical sealing was performed with the association of calcium hydroxide, 2\% chlorhexidine gel and zinc oxide (S.S. White Artigos Dentários Ltda., Rio de Janeiro, RJ, Brazil), in the proportion of 2:1:2. Next, access cavity was double-sealed with Coltosol and composite resin.

Table I First clinical and radiographic exam

\begin{tabular}{|c|c|c|c|c|c|c|c|c|c|c|}
\hline Tooth & $\begin{array}{l}\text { Cold pulp } \\
\text { sensibility } \\
\text { test }\end{array}$ & $\begin{array}{l}\text { Pulp } \\
\text { electric } \\
\text { test }\end{array}$ & $\begin{array}{l}\text { Vertical } \\
\text { percussion }\end{array}$ & $\begin{array}{l}\text { Horizontal } \\
\text { percussion }\end{array}$ & Mobility & $\begin{array}{l}\text { Spontaneous } \\
\text { pain }\end{array}$ & Abscess & $\begin{array}{l}\text { Sinus } \\
\text { tract }\end{array}$ & Palpation & $\begin{array}{l}\text { Periapical } \\
\text { lesion }\end{array}$ \\
\hline 12 & + & + & - & - & - & - & - & - & - & - \\
\hline II & - & - & + & + & - & - & - & + & + & + \\
\hline 21 & + & + & - & - & - & - & - & - & - & - \\
\hline 22 & + & + & - & - & - & - & - & - & - & - \\
\hline
\end{tabular}

*Cold pulp sensibility test (Endo Ice; Roeko, Langenau, Germany), electric test (Pulp Tester;Analytic Technology, Redmond,WA).
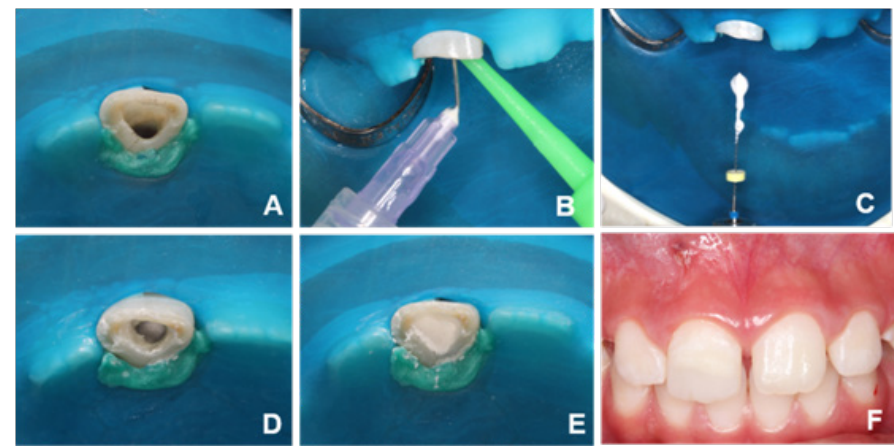

Figure I First appointment of pulp revascularization;A:Access cavity of maxillary right central incisor; B: Passive decontamination of the root canal; C: Insertion of intracanal medication (calcium hydroxide associated with $2 \%$ chlorhexidine gel) with a lentulo spiral; D: Root filling with intracanal medication; E: Cervical sealing with Coltosol; F: Crown restoration with composite resin and final clinical aspect.

Patient and her guardian were recommended to return for followup in each 3 months after pulp revascularization. However, they only returned to the Dental Trauma Service after 1 year of pulp revascularization, due to the recurrence of dental trauma 1 month previously. Patient's guardian reported that second trauma occurred with the impact of glass bottle. Clinical and radiographic exams (Table 2) showed crown fracture and sublimation of both maxillary central incisors, and leakage of pulp revascularization sealing of the right maxillary central incisor, leading to root canal infiltration. Even though, periapical healing, remission of clinical signs and symptoms, root wall thickness and apical closure were observed. Also, enamel and dentine fracture of the left maxillary central incisor was detected. Therefore, crown restoration with composite resin was immediately planned for the right and left maxillary central incisors. A second endodontic intervention with an alternative filling therapy of the right maxillary central incisor was accomplished. Tooth was decontaminated with manual mechanical preparation associated with $2 \%$ chlorhexidine gel and copious irrigation with saline solution. Then, root canal was filled with a filling paste previously proposed to teeth that suffered dental trauma. ${ }^{17}$ This paste is composed by the mixture of calcium hydroxide, $2 \%$ chlorhexidine gel and zinc oxide, in the proportion of 2:1:2, until reaching a firm consistency. The filling paste was inserted in increments, using medium and fine-mediumsized vertical condensors (Konne Indústria e Comércio de Materiais Odontológicos Ltda., Belo Horizonte, MG, Brazil). Initially, apical third was filled with increments and a control radiograph was performed to verify the apical limit. Following this, root canal full length was filled and other control radiograph was carried out to confirm compaction with absence of filling voids. Tooth was then sealed with Coltosol and restored with composite resin (Figure 2), and then radiographed. 
Table 2 Clinical and radiographic exam after recurrence of dental trauma

\begin{tabular}{|c|c|c|c|c|c|c|c|c|c|c|}
\hline Tooth & $\begin{array}{l}\text { Cold pulp } \\
\text { sensibility } \\
\text { test }\end{array}$ & $\begin{array}{l}\text { Pulp } \\
\text { electric } \\
\text { test }\end{array}$ & $\begin{array}{l}\text { Vertical } \\
\text { percussion }\end{array}$ & $\begin{array}{l}\text { Horizontal } \\
\text { percussion }\end{array}$ & Mobility & $\begin{array}{l}\text { Spontaneous } \\
\text { pain }\end{array}$ & Abscess & $\begin{array}{l}\text { Sinus } \\
\text { tract }\end{array}$ & Palpation & $\begin{array}{l}\text { Periapical } \\
\text { lesion }\end{array}$ \\
\hline 12 & + & + & - & - & - & - & - & - & - & - \\
\hline II & - & - & - & - & + & - & - & - & - & - \\
\hline 21 & + & + & - & - & + & - & - & - & - & - \\
\hline 22 & + & + & - & - & + & - & - & - & - & - \\
\hline
\end{tabular}

*Cold pulp sensibility test (Endo Ice; Roeko, Langenau, Germany), electric test (Pulp Tester;Analytic Technology, Redmond,WA).
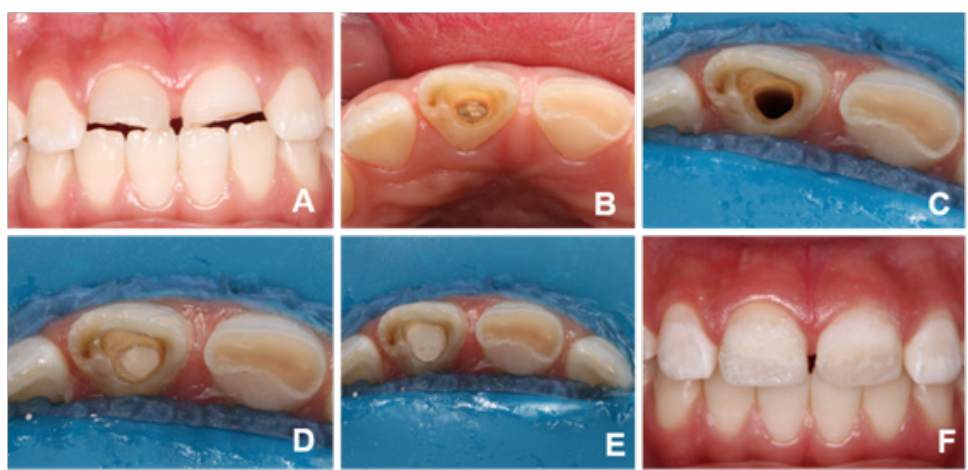

Figure 2 Tooth management in second trauma; A: Clinical aspect after second trauma; B: Presence of infiltration in cervical sealing of pulp revascularization; C: Root canal entrance after chemo mechanical preparation; D: Root canal filling with a filling paste; E: Cervical sealing with Coltosol; F: Crown restoration of maxillary central incisors with composite resin and final clinical aspect.

\section{Follow-up and outcomes}

Currently, the patient does not present any signs or symptoms and was recommended to return for follow-up in each 3 months. Patient is satisfied with the obtained results. Standard radiographic examinations showed evidence of maintenance of the status first observed after 1 years of pulp revascularization (Figures $3 \& 4$ ) briefly describes relevant data from this case report of as a timeline.

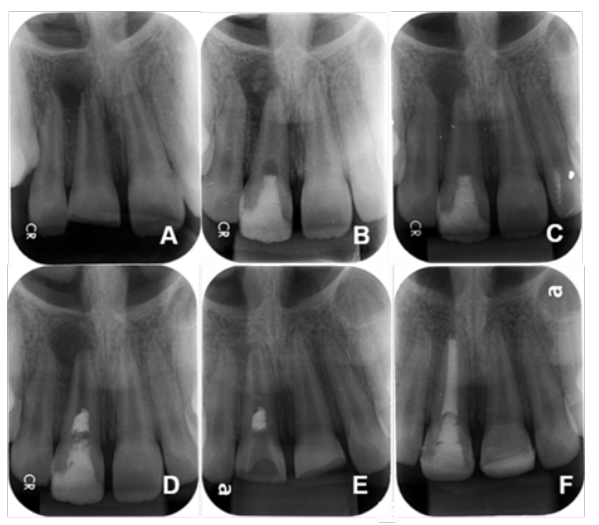

Figure 3 Radiographic evolution of the maxillary right central incisor; a. Initial radiographic aspect after the first dental trauma

b. Final radiograph of the first pulp revascularization session, with intra canal medication

c. Initial radiograph of the second session of pulp revascularization, after 3 weeks

d.Final radiograph after completing pulp revascularization procedure in the second appointment

e.Radiographic aspect after I year and second episode of dental trauma

f. Root canal filling with filling paste.

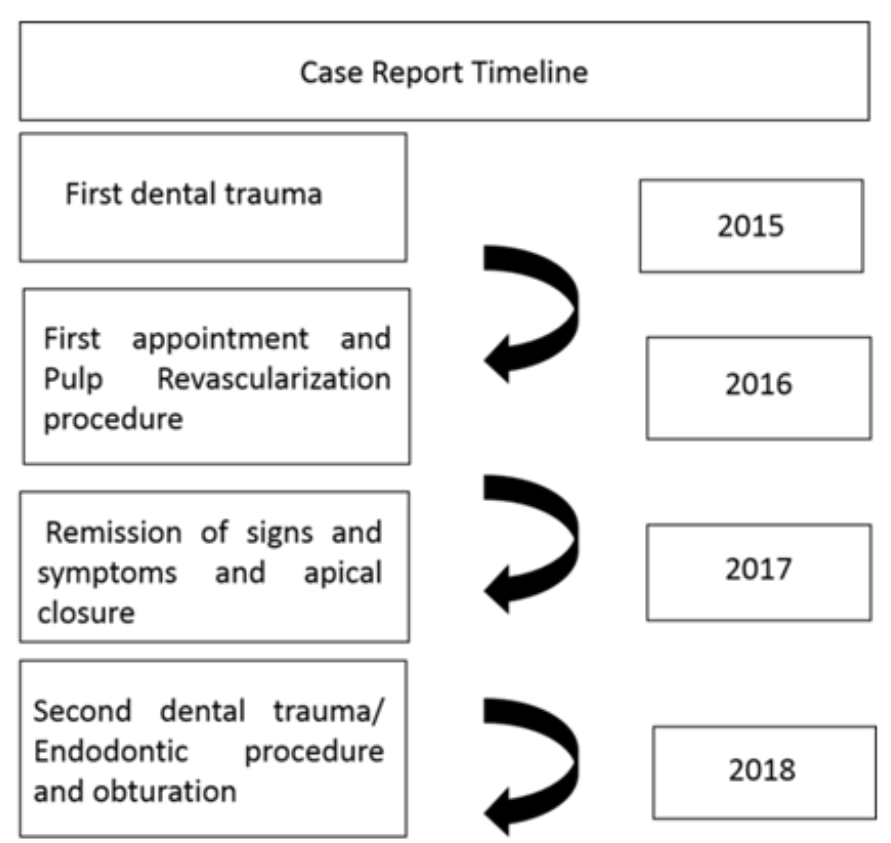

Figure 4 Timeline of relevant data from the case report.

\section{Discussion}

Dental trauma may lead to complications according to its severity, such as pulp necrosis. In these cases, stage of root development must be considered for the treatment of choice. Evidence supporting pulp revascularization procedures for this clinical scenario has gradually increase. ${ }^{9,18}$ Therefore, as facing a case of permanent immature necrotic tooth in the present report, the treatment of choice was pulp revascularization that was considered successful due to the remission 
of signs and symptoms, periapical bone healing, apical closure and formation of a mineralized tissue that yielded slight root wall thickness in apical region. Recurrence of dental trauma is known as a factor that interferes in endodontic treatment success, affecting the tooth prognosis irrespective if the trauma occurred before or after the beginning of the root canal treatment. ${ }^{4,6}$ This may be explained because a second impact causes severe damage in pulp and/or periodontal tissues, possibly leading to events of inflammatory reactions or even infection process that increases the risk of having complications such as external inflammatory root resorptions. ${ }^{5,19}$ Teeth that suffered repeated trauma have been reported to be kept in the oral cavity for a shorter period when compared to teeth that suffered only one dental trauma. ${ }^{4,6}$ In some cases, the second trauma lead to immediate tooth extraction. ${ }^{4}$ As a result, professionals must warn patients or patients' guardians regarding preventive measures of dental traumas, predisposing factors to traumatism and reduced chances of success in the endodontic treatment of cases of second trauma in the same tooth. Already known predisposing factors that raises the risk of multiple dental trauma include increased overjet with protrusion, inadequate lip closure, sports practice, and early ages (between 7-12 years old)..$^{5,8,20,21}$ Besides that, other causes have been reported, such as human behavior (e.g., risk-taking and emotionally stressful states) and presence of illness, learning difficulties or physical limitations., ${ }^{5,22}$

In the present case, the patient presented young age and inadequate lip closure increasing the chances of dental trauma recurrence. However, as this second trauma occurred in a revascularized tooth that was still in root development progress, this incident seems to be even more critical. As permanent immature teeth present thin dentinal walls and the traumatism impact weakens root structure, the risk of root fracture was higher. ${ }^{23,24}$ Fortunately, complications were restricted to loss of crown restoration and subluxation. It could be argued that the initial process of root development, resulted from pulp revascularization, strengthened dentinal walls and thus reduced the chance of root fracture. However, if the second dental trauma had not occurred and a longer period of pulp revascularization follow-up was carried out, a more significant increase in root wall thickness and root length could possibly have occurred. As second dental trauma episode lead to a severe damage in supporting tissues and the tooth already presented apical closure and root walls strengthening, the treatment of choice for the second intervention was an alternative obturation technique - the filling paste. Ideally, this material provides permanent root filling. The use of filling paste is an interesting approach for cases of severe dental trauma mainly because it is known to prevent external inflammatory root resorptions..$^{17,25}$ Moreover, it is low-cost and easyto-use, besides presenting high radiopacity and mineralizing tissues ability. ${ }^{25,26}$

\section{Conclusion}

Pulp revascularization is an effective therapy for permanent immature necrotic teeth that suffered dental trauma. However, there is a high risk of recurrence of dental trauma, which may interfere in the treatment success. Therefore, professionals should be prepared for the necessity of alternative measures and techniques according to the evolution of each case.

\section{Acknowledgements}

None.

\section{Conflict of interest}

The author declares that there is no conflict of interest.

\section{References}

1. Marcenes W, Alessi ON, Traebert J. Causes and prevalence of traumatic injuries to the permanent incisors of school children aged 12 years in Jaragua do Sul, Brazil. Int Dent J. 2000;50(2):87-92.

2. Traebert J, Peres MA, Blank V, et al. Prevalence of traumatic dental injury and associated factors among 12-year-old school children in Florianópolis, Brazil. Dent Traumatology. 2003;19(1):15-18.

3. Ruslin M, Wolff J, Boffano P, et al. Dental trauma in association with maxillofacial fractures: an epidemiological study. Dent Traumatol. 2015;31(4):318-323.

4. Rocha MJ, Cardoso M. Survival analysis of endodontically treated traumatized primary teeth. Dent Traumatol. 2007;23(6):340-347.

5. Glendor U. Epidemiology of traumatic dental injuries - a 12 year review of the literature. Dent Traumatol. 2008;24(6):603-611.

6. Diangelis AJ, Andreasen JO, Ebeleseder KA, et al. International Association of Dental Traumatology. International Association of Dental Traumatology guidelines for the management of traumatic dental injuries: 1. Fractures and luxations of permanent teeth. Dent Traumatol. 2012;28(1):2-12.

7. Malmgren B, Andreasen JO, Flores MT, et al. Guidelines for the Management of Traumatic Dental Injuries: 3. Injuries in the Primary Dentition. Pediatr Dent. 2017;39(6):420-428.

8. Andreasen JO, Andreasen FM, Andersson L, editors. Textbook and color atlas of traumatic injuries to the teeth, $4^{\text {th }}$ ed. Oxford: Blackwell;2007:411-427.

9. Kim SG, Malek M, Sigurdsson A, et al. Regenerative endodontics: a comprehensive review. Int Endod J. 2018.

10. Al Ansary MA, Day PF, Duggal MS, et al. Interventions for treatingtraumatized necrotic immature permanent anterior teeth: inducing a calcific barrier \& root strengthening. Dent Traumatol. 2009;25(4):367379.

11. Rafter M. Apexification: a review. Dent Traumatol. 2005;21(1):1-8.

12. Conde MCM, Chisini LA, Sarkis-Onofre R, et al. A scoping review of root canal revascularization: relevant aspects for clinical success and tissue formation. Int Endod J. 2017;50(9):860-874.

13. Galler KM. Clinical procedures for revitalization: current knowledge and considerations. Int Endod J. 2016;49(10):926-936.

14. Nagata JY, Rocha-Lima TF, Gomes BP, et al. Pulp revascularization for immature replanted teeth: a case report. Aust Dent J. 2015;60(3):416-420.

15. Kahler B, Rossi-Fedele G. A review of tooth discoloration after regenerative endodontic therapy. J Endod. 2016;42(4):563-569.

16. Timmerman A, Parashos P. Bleaching of a Discolored Tooth with Retrieval of Remnants after Successful Regenerative Endodontics. J Endod. 2018;44(1):93-97.

17. Soares AJ, Lima TFR, Nagata JY, et al. Intracanal dressing paste composed by calcium hydroxide, chlorhexidine and zinc oxide for the treatment of immature and mature traumatized teeth. Braz J Oral Sci. 2014;13(1):6-11.

18. Chen YP, Jovani-Sancho Mdel M, et al. Is revascularization of immature permanent teeth an effective and reproducible technique? Dent Traumatol. 2015;31(6):429-436.

19. Pissiotis A, Vanderas AP, Papagiannoulis L. Longitudinal study on types of injury, complications and treatment in permanent traumatized teeth with single and multiple dental trauma episodes. Dent Traumatol. 2007;23(4):222-225

20. Francisco SS, Filho FJ, Pinheiro ET, et al. Prevalence of traumatic dental injuries and associated factors among Brazilian schoolchildren. Oral Health Prev Dent. 2013;11(1):31-38. 
21. Corrêa-Faria P, Martins CC, Bönecker M, et al. Clinical factors and sociodemographic characteristics associated with dental trauma in children: a systematic review and meta-analysis. Dent Traumatol. 2016;32(5):367-78.

22. Soares TR, Fidalgo TK, Quirino AS, et al. Is caries a risk factor for dental trauma? A systematic review and meta-analysis. Dent Traumatol. 2017;33(1):4-12.

23. Andreasen JO, Farik B, Munksgaard EC. Long-term calcium hydroxide as a root canal dressing may increase risk of root fracture. Dental Traumatol. 2002;18(3):134-137.
24. Valera MC, Albuquerque MT, Yamasaki MC, et al. Fracture resistance of weakened bovine teeth after long-term use of calcium hydroxide. Dent Traumatol. 2015;31(5):385-389.

25. Soares AJ, Nagata JY, Casarin RC, et al. Apexification with a new intra-canal medicament: a multidisciplinary case report. Iran Endod J. 2012;7(3):165-170.

26. Souza-Filho FJ, Soares AJ, Vianna ML, et al. Antimicrobial effect and $\mathrm{pH}$ of chlorhexidine gel and calcium hydroxide alone and associated with other material. Braz Dent J. 2008;19(1):28-33. 